$\xi=-1$

\title{
Mathematical Model for the Manual Vibration Roller Drive Mechanism Investigation
}

\author{
Vasyl Lyutenko $^{1 *}$, Oleksandr Orysenko ${ }^{2}$, Vitaliy Nadobko ${ }^{3}$ \\ ${ }^{I}$ Poltava National Technical Yuri Kondratyuk University, Ukraine \\ ${ }^{2}$ Poltava National Technical Yuri Kondratyuk University, Ukraine \\ ${ }^{3}$ Poltava National Technical Yuri Kondratyuk University, Ukraine \\ *Corresponding Author E-Mail: V.Lutenko2012@Gmail.Com
}

\begin{abstract}
Dynamic loads calculation method in the manual vibration roller drive electric and mechanical systems is proposed. The technique takes into account the electromagnetic processes in the engine, elastic components fluidity, mass fluctuations, and damping in the elastic links. Transient process calculations results in electric and mechanical systems are presented.
\end{abstract}

Keywords: dynamic load, manual vibration roller, mathematical model, oscillatory occurrences, roller drive.

\section{Introduction}

One of the most important operations in the construction of any earthy construction is rolling [ $11-4]$. The quality of this operation depends not only on the strength, resistance, waterproofing of the structure, but also the equality of coverage, the duration of its service and the safety of motion. Compact vibrating technology (vibrating rollers, vibratory plasters) is intended for compaction of material and asphalt laying on road surface areas with a limited area. Compact vehicles are used during repairs on small streets, sidewalks, cycling paths and other objects, where due to its size, large equipment cannot be used.

The creation of rational and original designs of manual vibration rollers largely depends on the ability to match already known variants and to introduce new ones that meet the high level of modern technology.

Improvement of the drive manual vibration roller is also inextricably linked with drive systems dynamics and durability study.

\section{Research Problem}

\subsection{The Latest Sources and Publications Overview}

Vibration is a progressive rolling method that receives a significant distribution [1 - 8]. It explains vibrating machines different types' large quantity existing at this time. The lack of a qualified method for calculating modern vibration machines, including rollers, for building materials and mixtures surface rolling complicates their design and operation.

Works [5 - 8] are devoted to vibration equipment, including rollers study and analysis. In these works rollers are described by various calculation schemes, and their dynamic systems are considered as one-and two-mass oscillatory systems. It gives an opportunity to investigate the dynamic phenomena.

Works [8-13] on mechanical systems oscillatory occurrences study.

To ensure the high reliability results, mechanical vibrations should be investigated in close connection with electromagnetic processes [14 - 16], therefore dynamic processes mathematical model that includes both differential equations the roller drive system motion and the differential equation of electromagnetic phenomena in the asynchronous motor has been developed.

\subsection{General Problem Previously Unsolved Parts Selec- tion}

At present, drive roller loading conditions needs investigations during transient processes, especially when starting its drive.

When creating roller drives adequate mathematical models, mechanical and electrical systems are considered separately and it does not give a possibility to evaluate the electromechanical object actually and jointly consider mechanical and electromagnetic processes.

This work is aimed at solving, using the MathCAD application, manual vibration roller drive dynamics issues, which takes into account the electromagnetic transients in the electric drive (in the drive electric motor).

\subsection{Problem Statement}

The work purpose is to create manual vibration roller drive adequate physical process model, which is an electromechanical object, based on joint consideration of mechanical and electromagnetic oscillation occurrences.

\subsection{The Main Material}

Vibrating rollers represent a complex mechanical system that allows performing successfully soil consolidations, road surfaces and coatings while various constructions works.

As already noted, vibration rollers use the most common following types of drives: hydraulic drive, electric drive, as well as 
internal combustion engines.

In the manual vibration roller that is considering, the electric drive is used.

It can be stated that during the manual vibration roller work, the consolidation of soils, road bases (gravel) and coatings (layers of asphalt mix with the filler) is performed.

Dynamics process soils, road surfaces and coatings consolidation with manual vibration roller bolster is considered.

As the manual vibration roller is an elastic system consisting of metal structures (frame) and actuator, load factors that change in time and direction, the vibration rolling, inevitable fluctuations, result in additional incremental loads in sections.

To simplify the research process significantly, mathematical modeling is used.

Existing vibration rollers represent an elastic multi-mass system with degrees of freedom infinite number. The system includes masses having concentrated and distributed parameters.

Taking into account a manual vibration roller design peculiarities, its dynamics is considered under certain assumptions.

1. When the rotating elements masses of the manual vibration roller drive the elastic properties of the drive gears are not taken into account as their stiffness is many times higher than the stiffness of the roller structure itself: the absence of spaces in the kinematic drive configuration and masses synchronous displacement are also given.

2 . In some cases, the oscillation decay from external and internal friction is not taken into account, due to the fact that in the initial period, at small values of the resistance strength, they almost do not affect the oscillation processes.

3. Assume that in the process of oscillation there is a linear relationship between forces and deformations.

Transient processes occurring in the work of vibration rollers drive mechanisms, to a large extent determine the dynamic loads in the elements of the systems under consideration. The dynamics processes of starting and stopping the vibration drive mechanism is significantly influenced by the inertial and rigid parameters of the system elements. Start and stop the vibrating roller drive is performed when the compaction environment working process is performed.

When considering the dynamic phenomena that arise during the vibration roller drive start, mainly needs conditions of the load system taken the turn of the unbalanced shaft when compaction environment.

The calculation scheme is presented in Fig. 1, where $J_{1}$ - moment $M(t)=A_{0} u+A_{1} M^{\prime}(t)+A_{2} u^{2} z^{\prime \prime}(t)$

of the electric motor rotor inertia, reduced to the axis of rotation of $z^{\prime}(t)=d(t)$,

the vibration shaft, taking into account the masses of the rotating mechanisms; $J_{2}$ - total moment of vibration shaft inertia and the $d(t$ driven pulley relative to its own axis of the shaft rotation; $\phi_{1}=z(t), \phi_{1}=q(t)-$ coordinates of concentrated masses motion (angles of reference); $C$ - the combined coefficient of the wedge passage rigidity on tension.

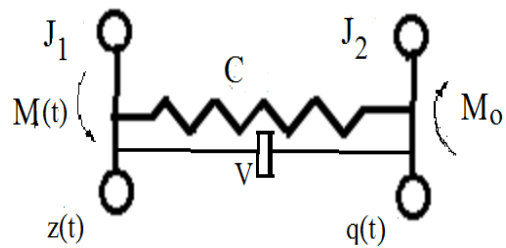

Fig.1: Loading mechanism calculation scheme of the manual vibration roller drive during the drive mechanism start

Summing all the system masses, elastic parts stiffness, as well as the forces make to the axis of unbalanced shaft rotation.

We will write the equation of motion in the following way:

$$
\begin{aligned}
& J_{1} \cdot z^{\prime \prime}(t)+C[z(t)-q(t)]+v\left[z^{\prime}(t)-q^{\prime}(t)\right]=M(t), \\
& J_{2} \cdot q^{\prime \prime}(t)-C[z(t)-q(t)]-v\left[z^{\prime}(t)-q^{\prime}(t)\right]=M_{0} .
\end{aligned}
$$$$
d^{\prime}(t)=-\frac{C}{J_{1}} z(t)-\frac{v}{J_{1}} d(t)+\frac{C}{J_{1}} q(t)+\frac{v}{J_{1}} n(t)+\frac{u}{J_{1}} M(t)
$$$$
q^{\prime}(t)=n(t)
$$

$$
M^{\prime}(t)=-\frac{A_{2} u^{2}}{A_{1}} z^{\prime}(t)+\frac{1}{A_{1}} M(t)-\frac{A_{0} u}{A_{1}},
$$$$
k(t)=\frac{u M(t)}{J_{1}}-\frac{z(t) C}{J_{1}}+\frac{q(t) C}{J_{1}}-\frac{v d(t)}{J_{1}}+\frac{v n(t)}{J_{1}},
$$$$
w(t)=-\frac{M_{0}}{J_{2}}+\frac{z(t) C}{J_{2}}-\frac{q(t) C}{J_{2}}-\frac{v d(t)}{J_{2}}+\frac{v n(t)}{J_{2}},
$$

Where $k(t), w(t)$ is angular acceleration, respectively, electric motor rotor and the unbalanced shaft.

After substituting the data taken from Tables 1 and 2 , it is obtained:

(1) $z^{\prime}(t)=d(t)$

$d^{\prime}(t)=27 M(t)-515668 z(t)-1 d(t)+515668 q(t)+1 \cdot n(t)$, $q^{\prime}(t)=n(t)$ 
$n^{\prime}(t)=3443929 z(t)+1 d(t)-3443929 q(t)-1 \cdot n(t)-507$,

$M^{\prime}(t)=-81 M(t)-3494 d(t)+275032$

$k(t)=27 M(t)-515668 z(t)-1 d(t)+515668 q(t)+1 \cdot n(t)$,

$w(t)=3443929 z(t)+1 d(t)-3443929 q(t)-1 \cdot n(t)-507$.

Initial conditions have the form:

$(t=0), \quad z(0)=0, \quad q(0)=0$,

$z^{\prime}(0)=0, \quad q^{\prime}(0)=0$,

$M(0)=0, \quad k(0)=0, \quad w(0)=0$.

The equations system solution (6) is made for the drive mechanism of a manual vibrator roller with an electric drive having the parameters given in Tables 1 and 2 .

To determine the accelerations in the system of differential equations (6) two acceleration equations are written $K(t)$ mass $J_{1}$ and $W(t)$ mass $J_{2}$.

Table 1: Manual vibrator roller drive parameters

\begin{tabular}{|c|c|c|}
\hline Parameters & Units of measurement & Numerical values \\
\hline$J_{1}$ & $\mathrm{~kg} \cdot \mathrm{m}^{2}$ & 0.031 \\
\hline$J_{2}$ & $\mathrm{~kg} \cdot \mathrm{m}^{2}$ & 0.0009 \\
\hline$M_{0}$ & $\mathrm{~N} \cdot \mathrm{m}$ & 2.84 \\
\hline$u$ & - & 1.2 \\
\hline$v$ & $\mathrm{~N} \cdot \mathrm{s}$ & 25 \\
\hline$C$ & $\mathrm{~N} \cdot \mathrm{m} / \mathrm{rad}$ & 19286 \\
\hline$\omega_{1}$ & $\mathrm{rad} / \mathrm{s}$ & 157 \\
\hline$\omega_{2}$ & $\mathrm{rad} / \mathrm{s}$ & 188 \\
\hline$r_{1}$ & $\mathrm{~m}$ & 0.075 \\
\hline$r_{2}$ & $\mathrm{~m}$ & 0.1 \\
\hline
\end{tabular}

Table 2: The value of a constant electric motor manual vibrator roller drive

\begin{tabular}{|c|c|}
\hline Parameters & Value \\
\hline Electric motor type & 4AA63B2y3, \\
& $\begin{array}{c}\mathrm{N}=0,55 \mathrm{~kW}, \\
\mathrm{n}=1500 \mathrm{r} / \mathrm{min}\end{array}$ \\
\hline Electric mode operation mode & Operating performance \\
\hline Angular speed of the electric motor rotor, rad/s & 157 \\
\hline Electric motor constant & 2842 \\
\hline$A_{0}$ & -0.0124 \\
\hline$A_{1}$ & -36.18 \\
\hline$A_{2}$ & \\
\hline
\end{tabular}

As a result of the solution a moment of the vibrator electric motor drive mechanism, angular displacement, speed and acceleration of the drive and the unbalanced shaft value is obtained.

Built on the basis of the performed calculations, the graph of the changing moment of the vibrator motor actuator in the function of time (Fig. 2, 4) shows that the acceleration of the drive lasts about 0.4 seconds from the moment it is turned on. The maximum value of the moment reaches $\mathrm{t}=0.3 \mathrm{~s}$ from the start beginning.

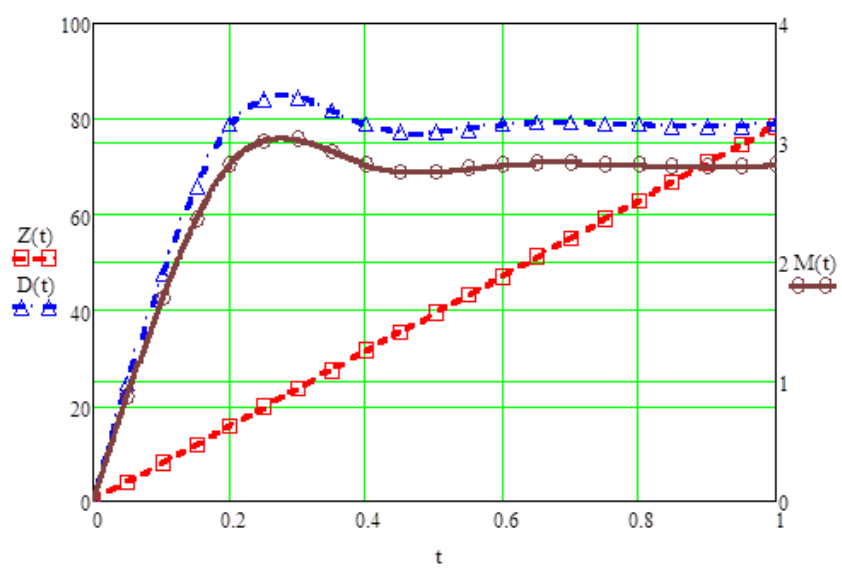

Fig. 2: Change of angular mass transfer $Z(t)=\phi_{1}$, rad, angular velocity $D(t)=Z^{\prime}(t)=\phi_{1}^{\prime}, \mathrm{rad} / \mathrm{c}$, and the moment of the motor drive vibrator $M(t), \mathrm{N} \cdot \mathrm{m}$, depending on time $\mathrm{t}, \mathrm{s}$ (without declining)

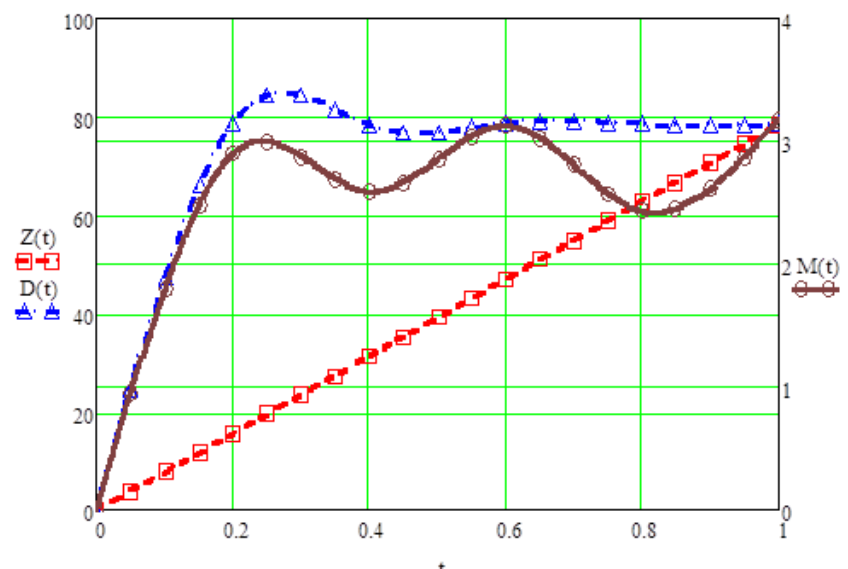

Fig. 3: Change of angular mass transfer $Z(t)=\phi_{1}$, rad, angular velocity $D(t)=Z^{\prime}(t)=\phi_{1}^{\prime}, \mathrm{rad} / \mathrm{c}$, and the moment of the motor drive vibrator $M(t), \mathrm{N} \cdot \mathrm{m}$, depending on time $\mathrm{t}, \mathrm{s}$ (without declining)

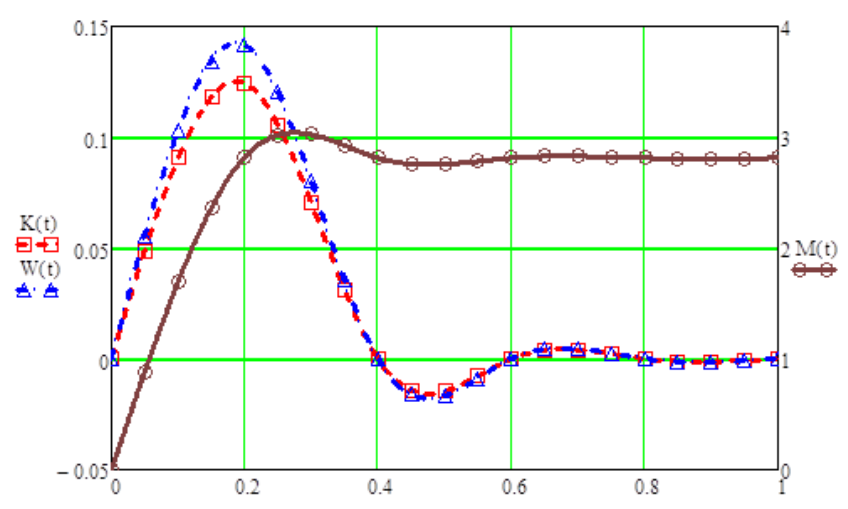

Fig.4: Changing the angular accelerations of the rotor electric motor $K(t)=\phi_{1}^{\prime \prime}=D^{\prime}(t)=Z^{\prime \prime}(t) \quad, \quad \mathrm{rad} / \mathrm{s}^{2}, \quad$ the unbalanced shaft $W(t)=\phi_{2}^{\prime \prime}=N^{\prime}(t)=Q^{\prime \prime}(t), \mathrm{rad} / \mathrm{s}^{2}$, and the moment of the vibrator drive motor $M(t), \mathrm{N} \cdot \mathrm{m}$, depending on the time $\mathrm{t}, \mathrm{s}$ (without a declining)

By solving the system of equations (6) with the application of the MathCAD system with the added mass $W(t)$ and mass $Z(t)=\phi_{1}$ acceleration $K(t)$ equations $Q(t)=\phi_{2}$, the values of accelerations of the electric drive vibrator motor $K(t)$ and the unbalanced shaft $W(t)$ are obtained (Fig. 4).

The graphs of changes in the acceleration of the unbalanced shaft $W(t)$ and the electric motor $K(t)$ (Fig. 4) constructed according 
to the performed calculations show that the acceleration has an oscillatory characteristics of the masses. Graph (Fig. 4) also show that after $0.8 \mathrm{~s}$ acceleration is practically zero, and the motion becomes steady rate. This is evident from the graph of the moment of vibrator drive motor $M(t)$.

Comparing the constructed graphs, both with and without the declining $v$ (Figures 2 and 3), we can conclude that the values differ substantially, and the specified parameters have more precise values when taking into account the declining $v$.

Transient processes shown in Fig. 2, 3, 4, are characterized by the oscillation of the electromagnetic moment, the angular velocity and acceleration of the electric motor, as well as the unbalanced shaft. Therefore, the calculation of the working modes of manual vibration roller must be performed basing on the equations of the electromechanical state of the system.

The use of numerical methods for integrating differential equations of motion and electromagnetic state allows touse the proposed method for calculating dynamic loads in the electromechanical and mechanical systems of vibration rollers.

\section{Conclusions}

1. The dynamics of the vibrator drive mechanism of a manual vibration roller is theoretically researched using mathematical software environment MathCAD in the work.

2. Integration differential motion and electromagnetic state equations numerous methods application allows using the proposed method for calculating dynamic loads in the electric and mechanical systems of vibration rollers.

3 . The study results of the drive vibration roller mechanism using the mathematical software environment MathCAD can be used to design, calculate and determine such vibration machines dynamic loads.

\section{References}

[1] Williams FHP, No Access compaction of Soils, Journal of the Institution of Civil Engineers, Vol.33, Issue 2, (1949), pp 73 - 99 https://doi.org/10.1680/IJOTI.1949.12931

[2] Canillas EC, Salokhe VM, Regression analysis of some factors influencing soil compaction, Soil and Tillage Research, Vol.61, Issues $3-4$, (2001), pp 167 - 178, https://doi.org/10.1016/S01671987(01)00206-9

[3] Canillas EC, Salokhe VM, Modeling compaction in agricultural soils, Journal of Terramechanics, Vol.39, Issue 2, (2002), pp $71-$ 84, https://doi.org/10.1016/S0022-4898(02)00007-1

[4] Scott RA, Pearce RW, Soil compaction by impact, Géotechnique, Vol.25, Issue 1, (1975), pp $19 \quad$ - 30, https://doi.org/10.1680/geot.1975.25.1.19

[5] Yunshi Yao, Zhongxu Feng, Shibin Chen, Zhifeng Zhang, Lijun Zhao, Wu Zhao, Design and Fabrication of a Road Roller with Double-Frequency Composed Vibration and Its Compaction Performance, Arabian Journal for Science and Engineering, Vol.39, Issue 12, (2014), pp 9219 - 9225, https://doi.org/10.1007/s13369014-1469-9

[6] Dzholdasbekov SU, Temirbekov YS, Shock-free Race Track of Road Roller Vibration Exciters, Proceedings of the World Congress on Engineering 2011, Vol III, WCE 2011, July 6 - 8, 2011, London, available online: http://www.iaeng.org/publication/WCE2011/WCE2011_pp25142517.pdf, last visit: 05.05.2018

[7] Long Yunjia Yang Yong, Wang Shumao, Wang Congling, Zhang Ping, Xie Shunqiang, Niu Yong, Auto-Propelled Chaotic Vibratory Heavy Road Roller, Journal of China agricultural University 200002, available online: http://en.cnki.com.cn/Article_en/CJFDTOTALNYDX200002003.htm, last visit: 05.05.2018

[8] Paul J. van Susante, Michael A. Mooney, Capturing Nonlinear Vibratory Roller Compactor Behavior through Lumped Parameter Modeling, Journal of Engineering Mechanics, Vol.134, Issue 8, (2008), https://doi.org/10.1061/(ASCE)0733-9399(2008)134:8(684)

[9] Kaplan D, Glass L, Understanding Nonlinear Dynamics, SpringerVerlag, New York, (1995), 420 p, https://doi.org/10.1007/978-14612-0823-5
[10] Hwang JH, Tu TY, Ground vibration due to dynamic compaction, Soil Dynamics and Earthquake Engineering, Vol.26, Issue 5, (2006), pp 337 - 346, https://doi.org/10.1016/j.soildyn.2005.12.004

[11] Mooney MA, Rinehart RV, Field Monitoring of Roller Vibration during Compaction of Subgrade Soil, Journal of Geotechnical and Geoenvironmental Engineering, Vol.133, Issue 3, (2007), https://doi.org/10.1061/(ASCE)1090-0241(2007)133:3(257)

[12] Broek D, Elementary Engineering Fracture Mechanics, Springer, Dordrecht, (1982), 469 p, https://doi.org/10.1007/978-94-009-43339

[13] Ray A, Patankan R, Fatigue crack growth under variable-amplitude loading: Part II - Code development and model validation, Applied mathematical modelling, Vol. 25, Issue 11, (2001), pp 995 - 1013, https://doi.org/10.1016/S0307-904X(01)00027-0

[14] Pujar JH, Kodad SF, Robust Sensorless Speed Control of Induction Motor with DTFC and Fuzzy Speed Regulator, International Journal of Electrical and Computer Engineering, Vol.5, No.9, (2011), pp 1041 - 1050, https://scholar.waset.org/1307-6892/8716

[15] Leiria A, Nunes P, Morched A, Barros M, Induction Motor Response to Voltage Dips, Electric Power Systems Research, № 76, iss. $\quad 8, \quad(2006), \quad$ pp $676 \quad-\quad 680$, https://doi.org/10.1016/j.epsr.2005.12.013

[16] Klyuchev V.I., Ogranichenie dinamicheskih nagruzok ehlektroprivoda, M.: EHnergiya, 1971. - 320 s. (In Russ.), available online: http://stanok-online.ru/literatura/elektroprivody/4868-ogranicheniedinamicheskih-nagruzok-elektroprivoda.html, last visit: 05.05.2018 